\title{
The Political Economy of Death in the Age of Information: A Critical Approach to the Digital Afterlife Industry
}

\author{
Carl Öhman ${ }^{1}$ (D) Luciano Floridi ${ }^{1,2}$
}

Received: 24 May 2017/ Accepted: 22 August 2017/Published online: 7 September 2017

(C) The Author(s) 2017. This article is an open access publication

\begin{abstract}
Online technologies enable vast amounts of data to outlive their producers online, thereby giving rise to a new, digital form of afterlife presence. Although researchers have begun investigating the nature of such presence, academic literature has until now failed to acknowledge the role of commercial interests in shaping it. The goal of this paper is to analyse what those interests are and what ethical consequences they may have. This goal is pursued in three steps. First, we introduce the concept of the Digital Afterlife Industry (DAI), and define it as an object of study. Second, we identify the politico-economic interests of the DAI. For this purpose, we develop an analytical approach based on an informational interpretation of Marxian economics. Third, we explain the practical manifestations of the interests using four real life cases. The findings expose the incentives of the DAI to alter what is referred to as the "informational bodies" of the dead, which in turn is to be seen as a violation of the principle of human dignity. To prevent such consequences, we argue that the ethical conventions that guide trade with remains of organic bodies may serve as a good model for future regulation of DAI.
\end{abstract}

Keywords Digital Afterlife Industry · Death · Political economy · Philosophy of information · Human dignity · Karl Marx

Carl Öhman

carl.j.ohman@gmail.com

1 Oxford Internet Institute, University of Oxford, 1 St Giles, Oxford OX1 3JS, UK

2 Alan Turing Institute, 96 Euston Road, London NW1 2DB, UK 


\section{Introduction}

The dead are becoming increasingly present in cyber space. For example, in 2012 the number of "dead" profiles on Facebook was estimated to be increasing at a rate of 19,000 daily (Death Reference Desk 2012). Sometime by the end of the century, depending on Facebook's user growth rate, the dead profiles are even expected to exceed the number of living user profiles (Brown 2016), thereby creating a form of "digital graveyard" (Ambrosino 2016). This development opens up new opportunities for commercial enterprises to monetise the digital afterlife of departed Internet users. But it also poses some severe challenges regarding the ethical status of such data.

Despite a growing body of academic literature on the phenomenon of digital afterlife (Graham et al. 2013), its economic and ethical aspects have hitherto drawn little attention. In particular, there is a lack of critical economic approaches in the literature (Meese et al. 2015, 416). Both sociological (Mitchell et al. 2012; Walter 2015) and legal studies (Mayer-Schönberger 2009; McCallig 2013) have mainly focused on cultural and social practices regarding death online. In doing so, they merely account for the role of technology and have thus left economics and ethics relatively unexplored. At the same time, purely ethical viewpoints (Stokes 2012; Wright 2014), although enlightening, often fail to situate the matter within a larger economic and political context. As a result, current research on digital afterlife tends to neglect the fact that the online presence of the dead is generally mediated by commercial platforms.

In this article, we provide a deeper empirical and theoretical understanding of death online by introducing the concept of the Digital Afterlife Industry (DAI) as an umbrella term for firms that commercialise the digital remains [term used by Lingel (2013)] of deceased Internet users. The DAI includes a wide range of actors: from small start-up applications, like Afternote and Departing.com, to technology giants, like Facebook and Google. It is reasonable to assume that the economic interests of such firms may play a part in shaping the nature of the online presence of the dead (Karppi 2013). For this reason we set out to investigate those interests, as well as their ethical consequences, by asking the following questions:

1. What is the DAI and what types of services are operating within it?

2. What are the political and economic interests of the DAI, and what ethically undesirable consequences may arise from them?

3. How do these interests manifest themselves in practice?

These questions are posed from what one may refer to as an infra-ethical perspective (Floridi 2013a, b). That is, they address the intersection of ethics and design. Answering them should put us in a better position to design social and economic infrastructures as a response to the undesirable consequences that are identified in this article. 


\section{The Emergence of an Industry}

Commercial enterprises were among the first to recognise the challenges and opportunities brought about by the increasing numbers of dead Internet users. At first, dealing with dead users appeared to pose a problem for businesses (McCallig 2013,11 ), but this soon gave rise to the development of a number of innovative services. In 2009, for example, Facebook began to allow bereaved family members to turn the profiles of their lost ones into memorial sites, spaces to meet, mourn, and collectively "keep in touch" with the deceased (Facebook 2016). Similarly, Google launched what they call an inactive account manager, which automatically informs the user's network about his/her death. In addition to the technology giants, a plethora of start-up companies are starting to exploit the "business" of death online (see "Appendix" for an overview). Regardless of their niche and size, such firms mark the beginning of an increased commercialisation of afterlife existence. As put by venture capitalist Dave Balter (Balter in Engel 2015), the "death industry" has become "ripe for disruption".

Because of its novelty, and despite the significance and magnitude of the issue, very little is currently known about the industry in terms of economics. For instance, in Graham et al.'s (2013) introduction to the special issue on the Death, Afterlife and Immortality of Bodies and Data in The Information Society, the economic perspective is almost entirely absent. While some, such as Aceti $(2015,7)$ has touched upon the connection between digital afterlife and capitalism, only two recent studies investigate the economics of digital afterlife explicitly: Karppi (2013) and Meese et al. (2015).

Karppi (2013) argues that social media sites are incentivised to keep dead users' information within their data economy rather than deleting it. Taking Facebook as his primary example, he further $(2013,14)$ claims that in the "noopolitics" of the site, the dead become "nodes that open up to other notes and other agencies" in a networked economy. Furthermore, he states that the position of the dead as nodes "thingifies" them and is argued to be the reason behind Facebook's decision to memorialise profiles rather than deleting them (Karppi 2013, 14).

On a similar note, Meese et al. (2015) speaks of an increasingly commercialised discourse of death in social media, arguing that this causes a "commercial and social push for the preservation of posthumous personhood" (Meese et al. 2015, 416). Mainly, this is suggested to be a discursive matter linked to the social mechanisms of social media at large. Despite touching upon the topic of political economy, neither Karppi, nor Meese et al. directly address the ethical dimension of the matter, nor do they acknowledge the industrial nature of digital afterlife existence of today, for which we account in the following pages.

\subsection{Death and Online Celebrity Culture}

Celebrity culture provides a valuable antecedent to the commercialisation of digital remains. Depending on the available ICT (Information and Communication Technology), the dead have always been able to remain present in society (Walter 
2015). The book, for instance, allowed previous generations to sustain so called "para-social" (Sherlock 2013, 168; Horton and Wohl 2006) relationships with historical figures like Jesus Christ or Mohammed the Prophet. However, the digital ICTs of today magnify the phenomenon immensely, not just in terms of the number of people involved, but also because they allow for much larger quantities and different kinds of information to outlive its producer. It thus gives rise to new forms of presence of, and communication with, the departed (for instance, the deaths of David Bowie and Prince), especially in terms of communal mourning and memorials (Church 2013).

The industrial commercialisation of the afterlife is a well-known phenomenon (Neate 2014; Sherlock 2013) within studies of celebrity culture. Celebrities may indeed continue to be profitable after their death. According to Forbes (2015), an artist like Michael Jackson has, for example, "made" more than $\$ 140 \mathrm{~m}$ since his death in 2009. Likewise, John Lennon has posthumously made \$12 m and Albert Einstein $\$ 11 \mathrm{~m}$. Clearly, in a world where everything is data, a person may outlive the death of his/her organic body, as argued by the philosopher Patrick Stokes (2012).

\subsection{Social Media Users as Micro Celebrities}

Digital and social media do not simply change the way celebrities are mourned and made present in society. As compellingly argued by Marwick (2013), they allow anyone with a computer to employ celebrity like strategies of communication. Subsequently, it can be argued that what was previously a celebrity privilege, to have an audience and a recorded life, has become democratised. This also implies that as social network users leave their information behind online when passing away, the kind of informational afterlife existence that was previously reserved for celebrities are now also becoming increasingly available to the general public (Walter 2015).

As has been the case with celebrity royalties and copyright, legal conflicts have also begun to appear over the informational assets left behind by ordinary Internet users (O'Brien 2015; Wright 2014; Lingel 2013). Since most user generated content is co-owned by the platform on which it is stored, ${ }^{1}$ Internet corporations often get full rights to user information upon the event of death (O'Brien 2015). This causes situations that closely resemble the typical conflict between record labels and family members of deceased music artists. Digital policy scholars have therefore repeatedly highlighted the alarming lack of legislation needed to address the conflict over data heritage (Carroll et al. 2015; Laouris 2015; McCallig 2013; Mayer-Schönberger 2009). In most countries, courts have no specific instructions regarding the issue, and therefore no guidelines to follow when endeavouring to reach a decision. The only exceptions can be found in the United States, where initiatives are currently being developed to create a federal standard (Carrol 2015).

\footnotetext{
${ }^{1}$ For instance, Facebook owns all the information one has produced on the platform. Similarly, Google owns one's entire search history.
} 
Apart from the legal issues, digital technology has also (as in the case of celebrities) given rise to new practices of grief (Brubaker et al. Brubaker et al. 2013; Kern et al. 2013) and even a societal reconceptualization of death itself (Sherlock 2013). For example, Mitchell et al. (2012) found that parents who create online memorial sites for their deceased children often keep the communication going for years after the child's death, indicating that even small pieces of information may function as surrogate for the deceased. Mitchell et al. (2012) explain this phenomenon as a result of the unique affordances of online technologies, in which the deceased may appear almost as if still alive, and they do subsequently warn against over usage of online memorials. Similarly, Stokes (2012) uses Floridian (2013) ethics to show that such data deserves to be treated as a moral patient in itself.

Despite the pressing nature of the issue, Internet users have, according to a study by Grimm and Chiasson (2014), paid little attention to questions of their digital afterlife. However, when asked, users are significantly more positive about having their data managed by non-profit organisations than corporate business (Grimm and Chiasson 2014, 7). Furthermore, a majority of users even prefer their information to be destroyed after dying (Grimm and Chiasson 2014, 7), an option strongly advocated by law scholar Victor Mayer Schönberger in his Delete: the virtue of forgetting the digital age (2009).

Commercialism is clearly a concern for consumers, and yet, nearly every aspect of death online is imbued with it. Matters of communal grief, as well as management of digital assets and the ethical and ontological status of digital remains are all concerns that are related to phenomena observable on, and therefore influenced by, commercial platforms. Despite this common denominator, there is yet no systematic analysis of the economic aspects characterising the phenomenon. In order to understand the dynamics of digital afterlife fully, an economic approach is therefore an essential building block. To begin structuring such an approach, the industry first needs to be mapped out.

\section{The Digital Afterlife Industry as an Object of Study}

In contrast to previous literature, we regard commercialization of digital afterlife as a specific object of study in itself. We shall refer to it as the Digital Afterlife Industry (DAI), an umbrella neologism that covers commercial enterprises that monetize death online. We define the DAI using three necessary and sufficient criteria.

The first criterion is production. In order to be classified as an industry, some form of good or service needs to be produced. Thus, the DAI only refers to activities of production, which distinguishes it from activities without a productive outcome such as private, unrecorded grief.

The second criterion is commercialism. Firms operating within the DAI produce goods, services or experiences (such as grief or closure) for the purpose of making profit, dealing with what they produce as commodities. ${ }^{2}$ This excludes non-profit

\footnotetext{
${ }^{2}$ As defined by Marx $(1867 / 2015,27)$, a commodity is (contrary to other forms of goods) an object or a service that is produced for commercial purposes.
} 
activities such as religious communities and self-made memorial sites, and also charities that, despite being productive (first criterion), do not make profit.

The third and last criterion is online usage of digital human remains. This refers to any informational content left by the deceased online, and distinguishes the DAI from three other types of industries: (1) commercialisation of physical funerals and offline digital activities, such as recorded audio messages and shifting images on tombstones; (2) biological immortality projects that enhance the durability of the organic body; and (3) businesses that deal with digital remains of non-human animals. Given the three suggested criteria, the DAI can be formally defined thus:

$\mathrm{DAI}={ }_{\text {def. }}$. any activity of production of commercial goods (or services) that involves online usage of digital remains.

On a practical/concrete level, "usage" simply refers to the specific aspect of digital afterlife that is addressed by a service, to whom the product is sold, and the need, which it is meant to fulfil. On a more abstract level, "usage" rather refers to the role of digital remains in the production process, which remains invariant as technology develops. While the latter is crucial for identifying the general interests of the industry, the next subsection focuses solely on the former, the practice of using digital remains.

\subsection{Organising Services Within the DAI}

There have been previous attempts to put services within various categories (Foot et al. 2005), but these are almost exclusively with regards to memorial sites. Comprehensive and systematic categorizations of the firms operating within the industry are thus rare, even if tutorials on the variety of services exist (Meese et al. 2015). As far as academic literature goes, the only systematic attempt to categorise different digital afterlife services is a short conference paper written by de Oliveira et al. (2015). Despite lacking a clear definition of the industry, the paper suggests four types of services: (A) Messaging Services, (B) Online Memorials, (C) Digital Heritage Management, and (D) Data Mining. ${ }^{3}$ While appearing intuitively accurate, these types lack empirical grounding as the authors do not present any methodology nor the process of producing the types. They are therefore difficult to operationalize and lack strict definitions. To obtain a more rigorous taxonomy, a systematic reexamination of the industry is necessary.

To ground the categorization in empirical data, we collected information about an initial list of 57 different firms ${ }^{4}$ using three main sources: (1) the list provided by the digital afterlife blog Thedigitalbeyond.com; (2) the list used in de Oliviera's study; and (3) the top 50 hits on Google with the search terms "digital afterlife service". The firms were then organized in a three-step procedure, with focus on the product offered to the users.

\footnotetext{
3 Our translation from Portuguese.

4 For a more detailed illustration of the procedure, see "Appendix".
} 
First, another layer was added to the initial list of firms, which consisted of a short summary of the product/service offered by each firm. As some firms offer more than one service, the total number of services/products offered numbered 72 . Second, the 72 products/services were merged into 14 more general groups with regards their character. For example, all services providing some kind of posthumous emailing (regardless of price and product design) were merged into one particular group, defined as "Posthumous emailing", as were services that in some way keep the user's profile posting on social media ("Posthumous Social Media Messaging"). The third step collapsed the 14 categories into four broad types: (A) Information Management Services, (B) Online Memorial Services, (C) Posthumous Messaging Services and (D) Re-creation Services. For example, groups involving emailing, continuous social media presence and posthumous video communication were collapsed into the broader type "Posthumous Messaging Services". While the outcome of this procedure largely overlaps with the types suggested by de Oliveira et al. (2015), the new definitions are more precise. They are also arrived to through a fully transparent process using empirical data (see "Appendix").

\section{(A) Information Management Services}

Definition Services that help users deal with problems regarding digital asset management that may arise as a consequence of their own or someone else's death.

Information management services create a form of digital will for their users, and ensure that assets are passed on (or destroyed) upon the event of death. Such services are typically delivered by small start-up companies like Everplans or Passwordbox.com. However, as Google recently introduced their "inactive account manager" option, many of the less advanced firms have become rather obsolete. At the same time, Google's entry to the business increases the importance of the market as a whole, as it becomes a part of the Gmail package, used by more than 1 billion people globally (Miller 2016).

Google's entry also makes it difficult to estimate the amount of capital that is being invested in the Information Management market, especially since their services are technically "free". Yet, a report released by the online security company McAfee (Smith 2011) showed that people on average put a value of $\$ 37,000$ on their digital assets ( $\$ 55,000$ for Americans). This certainly indicates that there is profit to be made. Recent investments are pointing in the same direction; in 2014, Everplans received $\$ 3.45 \mathrm{~m}$ in venture capital, likewise the venture capitalists OMERS Venture has since invested \$6 $\mathrm{m}$ in the platform Passwordbox, to mention only a few.

\section{(B) Posthumous Messaging Services}

Definition Services that, upon the death of the user, deliver online messages or other digital communicative content to appointed recipients.

The typical service sends out a message to the users, which-if unansweredtriggers a number of messages and/or other forms of digital content to be sent out to a certain number of people. Many firms that offer posthumous messaging combine it 
with some form of Information Management. It can be seen as a form of social insurance that one's last wishes and secrets will be passed down after one dies. In contrast to the Information Management Services, this kind of service has not been adapted by any of the mainstream firms. Whereas one or two messages are often free, almost every site has a premium version that varies in prices from $\$ 10$ to 50 per year, according to our investigation.

\section{(C) Online Memorial Services}

Definition Services that provide an online space for a deceased individual or group to be mourned and/or remembered.

Sites often include features such as logs and other forms of communication channels where the bereaved can mourn together as well as interact with the digital remains of the deceased. Users (bereaved friends and family) often upload photos, videos and other forms of informational entities, which functions as a form of digital grave. This kind of service is typically delivered by a start-up with around 50,000 users. Many services advertise themselves as free, but almost without exception there is some form of paid "premium" version. Similar to Google's entry to the Information Management Services, memorial start-ups are competing with Facebook, which currently hosts a vast majority of online memorials (despite the fact that memorials are not Facebook's primary purpose). As there are 1.65 billion current users who are yet to die, Facebook-memorials are facing a prosperous future.

\section{(D) Re-creation Services}

Definition Services that use personal data in order to generate new content replicating a dead person's social behaviour.

Re-creation services are sites that assemble digital remains in order to re-create the personality of the deceased. In contrast to simple messaging services, they do not just post previously produced data, but actually generate new messages based on one's online behavioural patterns. The SNS (Social Networking Site) Eter9 for example, uses Artificial Intelligence (AI) to create a virtual duplicate of the user, which is active in his or her absence. Unlike the other types, this kind of feature has (for obvious reasons) not been adapted by the main stream technology giants. Similar to the previous types, Re-creation Services are typically provided by an (often unstable) start-up company. The first commercial project Virtual Eternity was founded in 2012, but soon went out of business as they only managed to attract about 10,000 users. Lately, firms that are more successful have begun to emerge; for example, Eter9 has managed to increase its user base from 7 to 50 thousands during the last 6 months (at the time of writing). Similarly, MIT start-up Eterni.me has currently about 33,000 beta-subscriber.

Until now, the kind of systematic mapping and definition of the industry that is outlined above has been largely missing from academic literature. As pointed out before, the services are only described from the perspective of their usage of digital 
remains in a very concrete sense. To identify the general economic interests of the industry, one needs to consider the conceptual level too.

\section{Outlining a Critical Approach}

When addressing the general economic mechanisms of the industry, one cannot solely rely on empirical data, which is tied merely to the current firms on the market. Instead, our analysis addresses the economics of the phenomenon on a conceptual level. That is, it investigates what is independent of the current market. In order to describe the basic interests of the DAI we use the concepts of living and dead labour (Marx 2015, 163), [also used by Chung (2015) in a study of visualisation of the (un)dead in digital cinema]. Furthermore, the critical angle of this study requires an ethical dimension to be included in the analysis, which has largely been missing in previous research on the politics of the online dead (Aceti 2015; Meese et al. 2015; Karppi 2013). To extend our economic analysis into the realm of ethics, we therefore employ Marx's concept of the inorganic body and the theory of its alienation, as outlined by Marx in the Economic and Philosophic manuscripts of 1844 (1844/2000). However, instead of adapting a Marxist approach fully, we develop Marx's economic metaphor of the inorganic body into an ethical critique by interpreting it through the lens of Floridi's (2013a, b) defence of informational privacy, that is-as an informational body.

\subsection{Conceptualising the Economic Use of Digital Remains}

In Marx's economic philosophy, the activity of human work is sometimes referred to as living labour. The product of labour, its antithesis, is subsequently referred to as dead labour (Marx 2015, 163), or congealed labour. When accumulated and commodified, such congealed (dead) labour becomes capital. Capital in turn, can either be fixed, as in the case of machines or a factory, or circulating as in the case of money. When someone owns capital, invests in some means of production or invests in any form of resources, it becomes necessary for them to put these in use to produce more value.

Simplified, the role of capital (dead labour) can be described thus: For a capitalist seeking to make profit, tools (such as a saw) are useless unless worked by a labour force to produce new objects (commodities), such as a spinning wheel. However, the spinning wheel is just like the saw: if not sold or worked by another (human) labour force it too has no use for the capitalist. Therefore, even more labour power is demanded for the two objects to stay productive. Someone who has invested in a large number of tools must therefore make the investment worthwhile by ensuring they are worked by human labour, or face bankruptcy. In other words, dead labour demands living labour (human work) in order to stay productive. Hence, capital is sometimes likened to as an undead creature, or as put by Marx: "Capital is dead labour which, vampire-like, lives only by sucking living labour, and lives the more, the more labour it sucks" (Marx 2015, 163). 
In the context of DAI, the metaphor of the undead can be interpreted rather literally. When used in the process of creating value, deceased Internet users actually become a form of undead agency that demands life activity (labour) from the living in order to continue to live, that is-remain productive. Subsequently, we propose that digital remains can be understood as a form of capital, an undead creature that demands human life activity-living labour-in order to remain productive. It follows, that use of digital remains for commercial purposes, creates an interest in increasing either the sales of the remains, or consumers' interaction with it. Even "free" services such as Facebook have an incentive to attract consumers who produce surplus attention to be sold to third parties (see Fuchs and Sevignani 2013). Thus, firms using digital remains have an interest in increasing any form of (productive) posthumous interaction, irrespective of what this may entail (in the section Five we shall elabourate on some examples in more detail).

However, Marx does not only provide concepts to describe the production process, but also ties it to a normative standpoint, what one may regard as a form of ethic. In producing objects, one is simultaneously producing oneself-what Marx refers to as one's inorganic body (1844/2000, 32):

The object of labor is, therefore, the objectification of man's species- life: for he duplicates himself not only, as in consciousness, intellectually, but also actively, in reality, and therefore he sees himself in a world that he has created. In tearing away from man the object of his production, therefore, estranged labor tears from him his species-life, his real objectivity as a member of the species and transforms his advantage over animals into the disadvantage that his inorganic body [my italics], nature, is taken from him.

In the process of production, one's inner nature is objectified, ("duplicated") in the material object of one's labour. Consequentially, the loss of control of what and how one produces (as in capitalist production), is also the loss of control of one's inorganic body: oneself. When forced by the market to shape himself in a certain way, man thus becomes alienated from himself (Marx 1844/2000, 32). Alienated, meaning he becomes a stranger to himself, loosing what makes him human, his inherent right to shape himself. This is (as is illustrated in Sect. 4.2) where economics ties into ethics.

As for the DAI, the estrangement of man appears to take place after death. It lies in the fact that digital afterlife services have an incentive to shape one's digital remains, the product of one's work and online identity, according to what is profitable. That is, in order to attract more consumers (either paying with attention or money) services must shape and display digital remains in their most consumable form. Regardless of business model, of weather a firm is charging consumers or providing "free" (i.e. consumers pay with their attention) access to the digital remains, it must display this data in a way that will attract consumers. This can be illustrated with the following hypothetical scenario: two firms (A and B) compete on the same market. Both are delivering a product that displays digital remains of a deceased person. Assume that firm A displays the most accurate version of the deceased, while firm B displays the most "consumable" one. Which firm is more 
likely to reach greater market success? At the risk of being regarded as cynical, we would argue that the latter is.

A consumable and an accurate image is (albeit related) not the same thing. Take for example the custom of decorating tombstones with photos of the deceased, that exists in some countries. Naturally, photos depicting happy moments in a person's life are far more popular than realistic ones representing their final stage of life. The dead are depicted the way the bereaved want to remember them, not necessarily how the dead wanted to be remembered, and hardly ever as they could be remembered in the last day of their lives. (For a more detailed analysis of how economics may influence the depiction of suffering and death, see Montoya's (2012) analysis of images used in aid organisations).

In the DAI, remembrance of the dead becomes not only a matter of human sentiment, but also a matter of economic benefit. The dead are not only depicted the way the bereaved want to remember them, but in accordance with what is profitable, i.e. what is likely to be consumed. Digital afterlife services thus have an interest in displaying the most "consumable" (regardless of what that practically means), and not the most accurate version of the dead. Such illicit alteration of one's identity in the name of profit can be interpreted as a form of alienation.

But who precisely is alienated? Surely, Marx was never concerned with the "inorganic corpses" of workers. Moreover, his critique of capitalist political economy has largely been interpreted as a matter of property relations, of the rightful ownership of production. In our case, this is an insufficient interpretation. The dead cannot own property in the usual sense of the word, and hence one needs to step away from such a standpoint when analysing the DAI. In order to tie the economic interests outlined above to an ethics of digital remains, we therefore suggest an alternate interpretation. This interpretation is based on Floridi's (2013a, b) ontological defence of the right to informational privacy, through which Marx's inorganic body can be understood as an informational body.

\subsection{The Inorganic Body as an Informational Body}

At the heart of Floridian (2013) ethics lies the inherent right to control one's personal identity, which, according to Floridi is to be understood as an informational structure; a narrative constituted by everything that defines it: memories, biometrical information, search history, social data, and so on. Thus, people do not merely own their information, but are constituted by it, and exist through it. As Floridi $(2014,121)$ explains, we should relate to private data as being ours in the sense of "our body" rather than "our car". We are our own information and our personal data are our informational bodies.

Through this view the right to informational privacy can for instance be interpreted more adequately as the right to be in control of one's own body and thereby of one's own existence; not to have it altered, duplicated, or distributed without oneself being in control. The informational understanding the nature of the self and its ethical status has a small, but very important implication on how to read Marx. Consider, for instance, the excerpt quoted above from the Philosophical and economic manuscripts (Marx 1844/2000, 32). 
When Marx states that man "duplicates himself" through production, what exactly is it that is being duplicated? What is this essence of the self that can exist in two places; both in man himself and in the objects he produces? Floridi's interpretation of personal identity provides a possible answer: information. That is, information constitutive of one's personal identity to be more precise. If accepting that the essence of a human consists in her information, it follows that what Marx refers to as the inorganic body of man is to be seen as an informational body.

When understanding the inorganic body of man (what he produces) as an informational body, the alienating effects of (privately owned) labour appear to be closely related to violations of informational privacy. Just like informational privacy infringements, alienation is about losing control over one's informational body, i.e., over oneself. Marx $(1844 / 2000,30)$ indeed makes a similar argument in stating that in capitalist production "he [the worker] belongs, not to himself, but to another".

To both Marx and Floridi, being in control of one's identity (informational body) is the essence of the human condition. Marx $(1844 / 2000,31)$ refers to this condition as "conscious life activity", while Floridi $(2016,4)$ poetically describes it as "being able to be the masters of our [humans] own journeys, and keep our identities and our choices open". When someone else takes control over this "journey", and steers it in whatever direction profit demands, they take from us what it means to be human or, as suggested by Marx $(1844 / 2000,32)$, it "tears from him [the human] his species-life, his real objectivity as a member of the species".

To take control of a person's productive life activity, or to infringe his/her informational privacy, is therefore an aggression, not only to the specific individual, but also to humanity as such, to what Floridi (2016) refers to as human dignity. To maintain human dignity is to remain the master of one's existence, of one's own "journey" through the world. In contrast to the concept of ownership, this applies not only to the living, but is also relevant for those who are dead. Just like the concept of dignity applies regardless of a person's awareness or unawareness of having their privacy being compromised (Floridi 2013a, b), so does dignity apply regardless of whether the producer of data is alive or not. The informational (inorganic) body continues to have the right to be treated with the respect worthy of a (dead) human (see Stokes 2015 for a more detailed analysis), regardless of whether the person to which it belongs is alive or not.

Moving away from an ownership-based interpretation of the Marxian concepts, to an ontologically grounded one, makes the economic critique outlined above applicable to the DAI. The digital remains of the dead cannot be exploited in terms of being denied their rightful share of profit, but do nevertheless deserve the respect worthy of a human body (corpse)—not a mere instrument for revenue generation. They are therefore to be protected as such. The dead, just like the living, have the right not to be alienated from themselves, a right to human dignity. Just like a human corpse has a right to be treated with dignity, so have our digital remains. This does surely not mean that the remains are never to be touched, but offers a compelling critique towards their commercialisation.

As we have shown in this section, commercial enterprises have economic incentives to display digital remains of the dead, their informational bodies, primarily in accordance with what is profitable and not necessarily what is accurate 
(whatever that implies). In some cases, this means that consumers pay for interaction with the remains of the dead; in other cases, it means shaping the interactions so that they become as profitable (attention producing) as possible. Irrespective of which alternative is pursued, we argue that commercial alterations of the digital remains of the dead can and should be seen as an illicit infringement on human dignity.

\section{The Interests in Practice}

The interests and ethically undesirable consequences that were outlined in the previous section were defined on a rather abstract level. In practice, they are manifested, and thus become visible, only through concrete usage of digital remains. As previously explained, there are four ways of using digital remains on the current market: (A) Information Management Services, (B) Online Memorial Services, (C) Posthumous Messaging Services and (D) Re-creation Services. In this section, real cases from each type illustrate how the interests and ethical consequences manifest themselves in practice. As becomes clear, advanced services with access to personal data tend to give more room for violations of human dignity than rudimentary ones using little or insignificant amounts of information. There is less of a risk to distort an (dead) informational body merely consisting of a bank credentials than one that includes the complete social data of a lifetime. In other words, the larger the quantity and quality of information used in a service, the higher the risk of altering how it is being displayed, of violating the human dignity of the dead. Let us see how.

(A) Information Management Services. A typical Information Management Service is Capsoole, a company that allows their users to prepare for their passing by organising digital assets such as passwords, images and other types of information by sending it to appointed heirs. For Capsoole, digital remains take the role of raw material (Means of Production). Therefore, the firm has an abstract interest in increasing interaction with the remains. This means having the users pass on as much content as possible to their heirs, which in turn makes them more present in the lives of the bereaved.

The dead users are made posthumously present through emails containing information, with details such as the location of a certain possession, the deceased's funeral wishes, or passwords for social networking sites or subscriptions. While this must not necessarily be regarded as problematic, it is not coincidence that the architecture of the Capsoole website is designed to make the user purchase services that allow for more content and assets to be passed on-thereby moving the nature of their digital afterlife in the direction of more presence and more interaction with the bereaved. Expressed differently, this is an endeavour to shape the informational body of the dead to fit the demands of profit. However, as there is little room for Capsoole to alter the display of the information, it is unlikely to display the users in ways threatening human dignity. 
(B) Posthumous Messaging Services. A representative example of Posthumous Messaging Services is the firm Heavenote (2016a), which allows their users to posthumously send various types of content to appointed recipients. The afterlife presence of the dead thus takes the role of a commodity, a service to be consumed. However, the site does not only provide a service; it is also designed to steer the usage of this service in a specific direction-to produce a more profitable afterlife. For every free feature the user chooses, a paid option with more data is suggested, such as: "you can record $30 \mathrm{~s}$ video, go Premium and get $10 \mathrm{~min}$ of video recording in each message" (Heavenote 2016a). Likewise, a quarter (roughly) of the user interface is covered with ads to promote premium or "ambassador" 5 options, which both entail changes in the nature of the user's afterlife. In addition to the design of the user interface, one can also see the abstract economic interests manifested in Heavenote's adverts (Heavenote 2016b):

Taking your digital afterlife into your own hands is one of the nicest things you can do for those who care about you [...]. Not only will you be able to give a message that might be the single greatest thing you could do for them, but you can also show a handy amount of foresight and impress all of those friends that will be gathered upon your death. Digital afterlife planning will be that last act of reminding people of how great you were in life, trust us. Try sending a message for free if you aren't sold.

The excerpt is illustrative of how the abstract interest in "consumability" manifests itself concretely in the Posthumous Messaging Services. The discourse is aiming to increase productivity (social interaction), and thereby to alter the user's digital afterlife. The site is discursively and architecturally designed to promote a profitable digital afterlife.

(C) Online Memorial Services. Differently from the mere messaging sites, memorials often display more information, and use a larger piece of the informational body of the dead. While some are free (i.e. capitalise on the surplus attention of the mourning) others charge the users. In both cases, firms have an interest in maximising the "consumability" of the digital remains. One can see this interest manifested in the various attempts to make memorials attract visitors. Without the request of the bereaved users, some sites even put headings, in the style of "He is much loved and will always be remembered by all his friends and family" (Fowler 2014), on the memorialisation of the deceased. Some sites also add background music, and clipboard pictures of doves and sunsets (Fowler 2014).

Due to its size and central position in society, the most relevant example of Online Memorial Services is Facebook. Facebook "memorializes" the profiles of their dead users, and uses them as a means to produce surplus attention and user activity from the bereaved, which in turn can be sold to a third party. For instance, when family and friends keep using a memorialised profile as a shared space for grief [as has become everyday practices for many in the West (Brubaker et al. 2013, 154)], they also keep exposing themselves to Facebook's targeted advertisement. The interests of the site are thus to maximise the labour power (here in the form of

\footnotetext{
5 To become an ambassador one has to invite friends to use the service. As a reward, one gets more data to use.
} 
attention/consumption) put into the memorialised profiles, that is, to maximize interaction.

The interest in maximised interaction is manifested in features (Memorialization and Legacy Contact) that allow for continuous interaction with, and consumption of, the profile of the dead. While it becomes impossible to log into the account, Facebook-friends of the deceased may still visit the profile and post messages. To facilitate such communication, Facebook also allows a "legacy contact" (Facebook 2015) to manage the profile of the deceased. Gradually, Facebook is moving towards a solution that allows for more interaction with the deceased. They are making the dead increasingly "alive" or, expressed differently, undead, as the profiles demands activity from the living users in order to remain productive. These are typical illustrations of how the commercial nature of the DAI may affect and alter the informational remains of the dead to fit a more commercial purpose.

(D) Re-creation Services. Services that aim to re-create the personality of the dead do naturally demand vast amounts of social data in order to perform. Due to the large quantities (and quality) of information, it is likely that the interests of the firm may influence the identity of the digital remains. One example is the social network site Eter9.com. It is a social network where dead users live on as so called "Niners", a form of AI-agents that replicate users' behaviour and manages the account while the user is offline, or dies (Eter9.com 2016). In theory, the site's interest is twofold: to increase interaction with the digital remains of the dead (the Niners) and thus to make that interaction as consumable as possible.

Eter9's economic interests are manifested in the way the "Niners" are programmed. While the user is offline, they are created to seek contact autonomously with other organic users of the platform. In doing so, they create more connections, interactions, and, ultimately, value for the firm. Simply put, the Niners are programmed to be consumable. This "consumability" can be seen as an incentive to alter a user's informational remains. The Niner left behind by an antisocial user will for instance be more prone to social interaction than the person it replicates, since it is more productive to make connections (i.e. increase user activity and attention) than not. This is a practical example of how the abstract interests identified in the previous section play out in real businesses. It is also a direct example of the ethically undesirable consequences that arise as productivity is maximized, and as the users loose of their control over their (dead) informational bodies.

The above cases illustrate the practical manifestation of the abstract interests and ethical consequences outlined in the previous sections. One may argue, that the possibility of altering the digital remains of the dead (and thereby violating their human dignity) progresses as services become more technologically advanced and get access to more rich information. However, while all services have economic incentives to maximise production, one should not expect firms to maximise productivity in every way possible. This is because the productivity of digital remains is not the sole factor determining market success but is instead negotiated with numerous other factors. In the following section, we shall discuss regulatory 
response as such a factor, and what ethical principles that should guide this response.

\section{Summary and Discussion}

This article set out to provide a more precise understanding of the economics and ethical consequences of the DAI. The three research questions that were posed to pursue this purpose have now been answered. In summarising the results, this final section also discusses their implications, especially with regards to their role in shaping a regulatory response to the DAI. This means that two things are broadly discussed: how the findings of this study contribute to the general understanding of digital afterlife, and how this understanding may inform regulatory action.

\subsection{Conceptualising the Digital Afterlife}

Once its frames are defined, the very concept of the DAI allows one to see a connection between a number of seemingly different phenomena. Furthermore, the various businesses dealing with death on the Internet appear as practical manifestations of the same (abstract) economic mechanisms. Consequently, the study ties together several different research areas. It allows one to identify systematically connections between policy oriented (Laouris 2015; McCallig 2013), philosophical (Stokes 2015; Swan and Howard 2012; Steinhart; 2007) and more empirically grounded research (Grimm and Chiasson 2014; Mitchell et al. 2012), as these research fields can all be related to the economics of digital afterlife.

As we become aware of the economic interests underlying digital afterlife firms, we are able not only to see ties between previous research findings, but also to reinterpret them. One example is Mitchell et al. (2012) study of online memorials for deceased children, where the authors point out "the affordances of the Web" (Mitchell et al. 2012, 28) as a driving cause behind prolonged grief:

[...] under the guise of addressing or even treating parental grief, on-line memorials may do more than simply accommodate that grief; they may perpetuate it. By enabling the deceased to persist, parenting to continue, and grief to be continually communicated, acknowledged and legitimated within a community of bereaved parents and a wider public, the Web affords an ongoing grief that is unhinged partially from longstanding ideas of 'closure', privacy, and a separation of the living and the dead.

The analysis provided in this article suggests a reinterpretation of such findings not just as a consequence of new ICTs but also, more specifically, as a consequence of their economic role in the production process. It is not the Web itself, but the way it is utilized in an economic system that perpetuates grief. Additionally, our findings shift the focus from being solely about the consequences for the bereaved to being 
also about the rights and "well-being" of the informational remains as moral patients in themselves.

The same kind of improvement can be made for theoretically oriented research. One example is Walter's (2015) argument about the societal presence of the dead and its historical dependence on the affordances of ICTs. While it is an accurate observation that digital media is changing the presence of the dead, the statement can be further nuanced. It is rather technology's role as a commodity or means in the production process that is the driving force in shaping the presence of the dead. As this study has illustrated, technology's role in mediating the presence of the dead is embedded in human practices, and human practice is in turn a matter of human (ethical) decision-making.

The ethical and the economic dimensions of the DAI intersect in the concept of the informational body. The metaphor is economic (Marxian), insofar as it shows the relationship between oneself and what one produces, namely information. It is ethical (Floridian), insofar as it makes this information in itself a moral patient. While other researchers (Karppi 2013; Meese et al. 2015) have also noted the interests in keeping the dead within the networked economies of social media, their arguments have not illuminated fully the ethical dimensions of the matter, nor the mechanisms behind them. While the lens of discourse used by Meese et al. (and to some extent Karppi) has provided important insights into the commercialisation of death online, it does not fully explain its political economy. We would hence like to add to their findings that discourse should be seen as a result, and not the cause, of the mechanisms that drive commercialisation of death online.

\subsection{Shaping a Response to the Industry}

When digital remains, as suggested in this study, are seen as remains of an informational human body, the problem of the DAI finally emerges as a commercial (and illegitimate) alteration of this body, which in turn is a result of politicoeconomic interests. Furthermore, the body metaphor can be seen as an invitation for legislators who deal with the DAI to seek inspiration from trade regulations of the remains of organic bodies. While Floridi (2013a, b, 245) has already compared informational privacy infringement with organ trade, death adds a new dimension to the analogy. When a person passes away, their organic body continues to hold some of the rights of the person. For instance, it cannot be traded or altered without the explicit consent of the individual to which it belonged. The comparison is however not perfect; restrictions can still be motivated with reference to the wellbeing of the bereaved, rather than the body's own inherent right to respect and dignity.

A better comparison may be with archaeological and medical museums, which have a great deal in common with the DAI. Both deal with objects that are difficult to allocate to a specific owner (see for instance Pearson 1999, 191), and both are displaying these objects for the living to consume (Alberti and Hallam 2013, 3). Furthermore, as many collections now become digitalised and made available online (Alberti and Hallam 2013, 13) the connection becomes even more striking.

Respect for ancient human remains (without any known descendants) cannot be correlated with reference to the wellbeing of their bereaved. And yet, many 
intuitively feel a responsibility to respect the moral status of such objects, namely $a$ respect for the body in itself. For these reasons, it is no surprise to find that the international museum codes of ethics that regulate exhibitions of human remains are rooted in the very principal of human dignity (ICOM 1986, 6) - the very same principle on which the Floridian (2016) notion of informational privacy is founded.

While the definition of human dignity may vary in different cultural contexts (Montoya 2012), there are some situations on which most of us will intuitively agree. We do not, for instance, put a Santa hat on Ötzi the Iceman to attract more museum visitors around Christmas, nor do we accept ghost tours in the tomb of Tutankhamun (despite our disbelief in the ancient gods of Egypt). In archaeological excavations of graves, bodies are even reburied after having been examined by researchers (Pearson 1999, 186). Similarly, there is reason to protect the online dead from undignified forms of commercialisation.

Hitherto, the DAI have seldom demonstrated the same monstrosity as the Ötzi the Iceman-example. Yet, there are plenty of examples of how an unregulated industry may come to look in the near future. In a recent news story on Unilad.com, photos from an open coffin-funeral were published, where the photographer had used a Snapchat filter to swap his own face with the deceased's (Roberts 2016). A dog nose and ears were also jokingly added using the same application. In a matter of less than 2 days, the article gained significant attention-more than 7500 shares, and almost 46,000 votes on the attached question "how fucked up is this on a scale of one to absolutely fucked?", a good source of revenue for Unilad.com. Despite not being a digital afterlife service, the example illustrates the mechanisms that have been explored in this article, which result in being a violation of human dignity.

The Unilad.com example is a single and extreme case, but it is also a good illustration of a larger phenomenon. The physical body of the deceased was left untouched, but a piece of the informational body (the digital picture) was altered and distributed in the name of commerce. Yet, the action is intuitively repulsive in the same way as if the dog nose would have been put on the physical body and not the photo. The findings of this article clarify and justify this repulsiveness, phrasing it as the deceased's loss of control of his informational (inorganic) body; as a violation of human dignity. The findings also show how such situations are linked to some specific economic mechanisms. They provide a language, a way of thinking about the presence of the online dead, which in turn offers a direction for our practical response.

At the beginning of this article, we argued that answering the research questions would put us in a better position to design social and economic infrastructures as a response to the undesirable consequences of the DAI. We have done so by suggesting that the ethical principles upon which the DAI is to be regulated should be the same as those that guide archaeological museums that exhibit remains of organic bodies: human dignity. The next step required will be a detailed analysis of how the regulation of organic remains translates to the realm of the DAI. This, however, is a topic for future research. 


\section{Concluding Comments}

To summarise, the contribution of this article is twofold. It has identified and constructed a conceptual map of the economics of the DAI, and it has deconstructed its ethical dimensions. Having done so, the article raises a set of new questions. What should be the role of commercial enterprises in managing the data of the dead? How do we design social, economic and regulatory infrastructures that render a respectful attitude from the industry? We have only begun addressing these questions in mature information societies. Yet, two things are already clear: that the Internet will continue to be an integral part of everyday life and that humans will (at least in the organic sense) continue to die. The dead are, and will continue to be, increasingly present online. It is up to us as a society to decide to what extent, and under what circumstances, this presence is to be influenced by the industry that mediates it.

Open Access This article is distributed under the terms of the Creative Commons Attribution 4.0 International License (http://creativecommons.org/licenses/by/4.0/), which permits unrestricted use, distribution, and reproduction in any medium, provided you give appropriate credit to the original author(s) and the source, provide a link to the Creative Commons license, and indicate if changes were made. 


\section{Appendix: Organisation of Concrete Usages of Digital Remains}

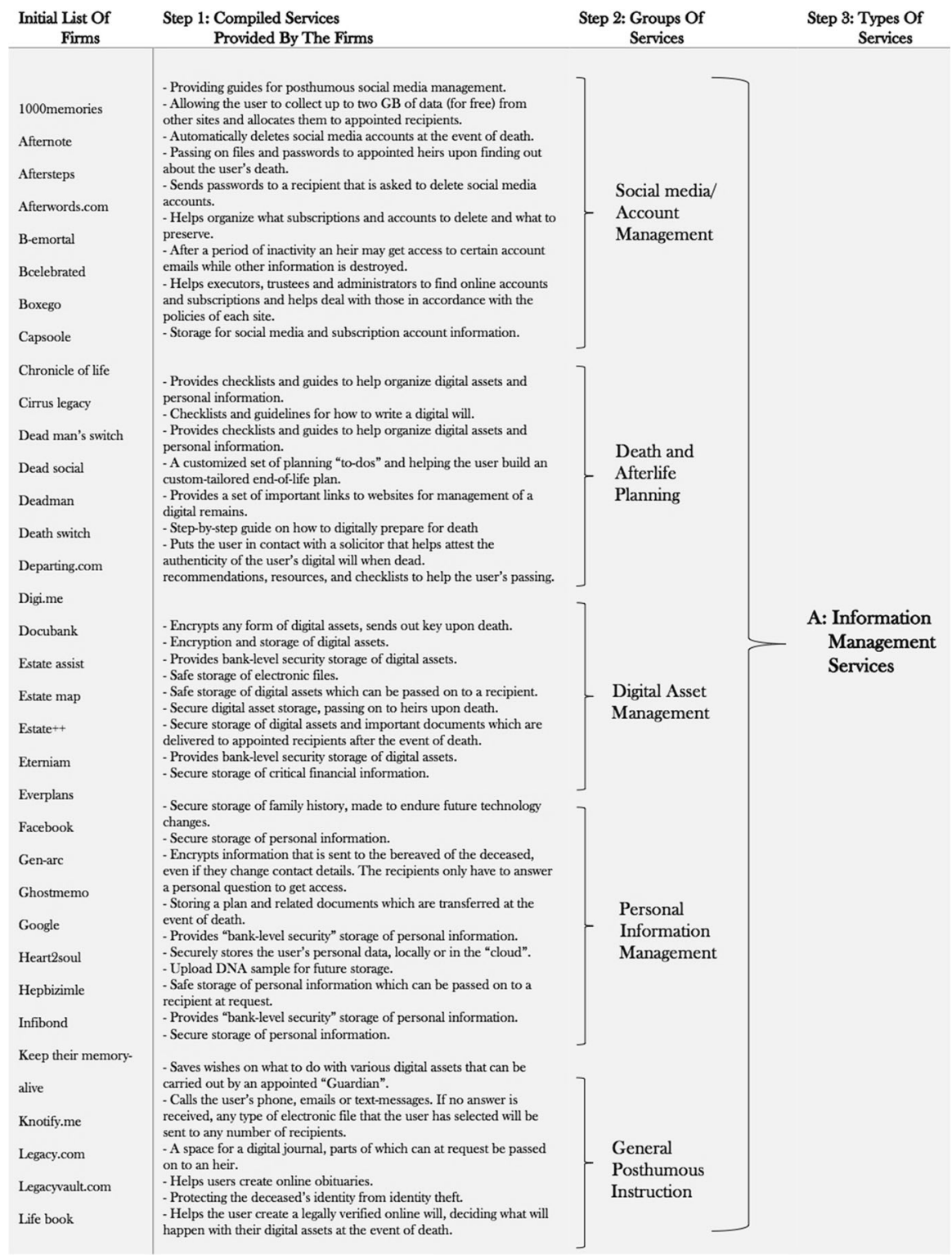




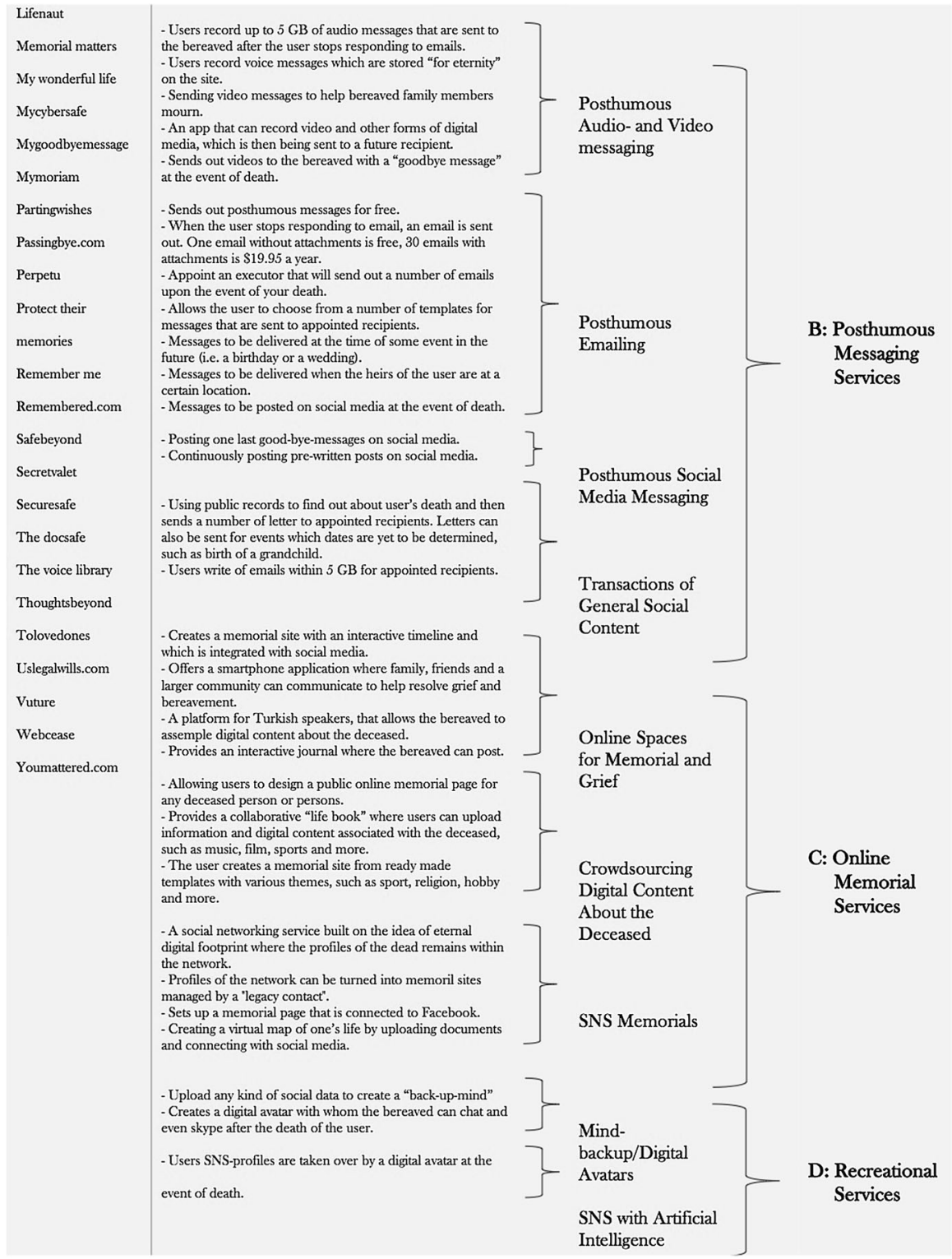

\section{References}

Aceti, L. (2015). Eternally present and eternally absent: The cultural politics of a thanatophobic Internet and its visual representations of artificial existences. Mortality, 20(4), 319-333.

Alberti, S., \& Hallam, E. (2013). Medical museums: Past, present, future. Retrieved from: https://www. researchgate.net/publication/273506763_Medical_Museums_Past_Present_Future. 
Ambrosino, B. (2016). Facebook as a growing and unstoppable graveyard. BBC.com, March 14. http:// www.bbc.com/future/story/20160313-the-unstoppable-rise-of-the-facebook-dead. Accessed 1 August 2016.

Brown, K. V. (2016). We calculated the year dead people on Facebook could outnumber the living. Fusion.net, April 3. http://fusion.net/story/276237/the-number-of-dead-people-on-facebook-willsoon-outnumber-the-living/. Accessed 1 August 2016.

Brubaker, J. R., Hayes, G. R., \& Dourish, P. (2013). Beyond the grave: Facebook as a site for the expansion of death and mourning. The Information Society, 29, 152-163. Published with license by Taylor \& Francis. ISSN: 0197-2243 print/1087-6537. doi:10.1080/01972243.2013.777300.

Carrol, E. (2015, Sep 26). Final revised UFADA now available. Retrieved from: http://www. thedigitalbeyond.com/2015/09/final-revised-ufada-now-available/.

Carrol, E., \& Romaro, J. (2011). Your digital afterlife: When Facebook, Flickr and Twitter are your estate, what's your legacy?. Berkeley, CA: New Riders.

Carroll, E., Romano, J., Carroll, E., Romano, J., Mitchell, L. M., Stephenson, P. H., et al. (2015). Your digital afterlives: Computational theories of life after death. Minds and Machines, 17(4), 363-379. doi:10.5172/hesr.2012.21.4.413.

Chung, H. J. (2015). The reanimation of the digital (un)dead, or how to regenerate bodies in digital cinema. Visual Studies, 30(1), 54-67.

Church, S. H. (2013). Digital gravescapes: Digital memorializing on Facebook, 2243, 148-189. doi:10. 1080/01972243.2013.777309.

de Oliveira, J., Reis, L. P., \& Amaral, L. (2015). Plataforms for digital heritage management. In 2015 10th Iberian Conference on Information Systems and Technologies (CISTI) (pp. 1-6). IEEE. doi:10. 1109/CISTI.2015.7170505.

Death Reference Desk. (2012). 19,000 Facebook users die each day. Here is how FB's memorialization mode works, February 5. http://www.deathreferencedesk.org/2012/02/05/19000-facebook-users-dieeach-day-here-is-how-fbs-memorialization-mode-works/. Accessed 1 August 2016.

Engel, J. (2015). Death in the digital age: Tech startups help us cope with mortality. Xonomy.com, October 28. http://www.xconomy.com/boston/2015/10/28/deathin-the-digital-age-tech-startups-help-uscope-with-mortality. Accessed 1 August 2016.

Eter9.com. (2016). About. Retrieved from: https://www.eter9.com/help/about.

Facebook. (2015). Adding a legacy contact, February 12. http://newsroom.fb.com/news/2015/02/addinga-legacy-contact/. Accessed 1 August 2016.

Facebook. (2016). Memorialized accounts. https://www.facebook.com/help/1506822589577997. Accessed 1 August 2016.

Floridi, L. (2013a). The ethics of information. Oxford: Oxford University Press.

Floridi, L. (2013b). Distributed morality in an information society. Science and Engineering Ethics, 19(3), 727-743. doi:10.1007/s11948-012-9413-4.

Floridi, L. (2014). The fourth revolution-How the infosphere is reshaping human reality. Oxford: Oxford University Press.

Floridi, L. (2016). On human dignity as a foundation for the right to privacy. Philosophy and Technology. doi:10.1007/s13347-016-022.

Foot, K., Warnick, B., \& Schneider, S. M. (2005). Web-based memorializing after September 11: Toward a conceptual framework. Journal of Computer-Mediated Communication, 11(1), 72-96.

Forbes. (2015). Top-earning dead celebrities 2015. Forbes.com. Retrieved from: http://www.forbes.com/ dead-celebrities/\#524884ce6a51.

Fowler, G. (2014). Online memorial services: After a death, celebrating a life online. The Wall Street Journal, January 28. http://www.wsj.com/articles/SB100014240527023035532045793487522 62042642. Accessed 1 August 2016.

Fuchs, C., \& Sevignani, S. (2013). What is digital labour? What is digital work? What's their difference? And why do these questions matter for understanding social media? TripleC, 11, 237-293.

Graham, C., Gibbs, M., \& Aceti, L. (2013). Introduction to the special issue on the death, afterlife, and immortality of bodies and data. The Information Society, 29(3), 133-141. doi:10.1080/01972243. 2013.777296.

Grimm, C., \& Chiasson, S. (2014). Survey on the fate of digital footprints after death. Usec'14, (February). https://cs.carleton.ca/sites/default/files/tr/TR-14-01.pdf. Accessed 1 August 2016.

Heavenote. (2016a). Create your first message. https://www.heavenote.com/. Accessed 1 August 2016.

Heavenote. (2016b). Why we all need a plan for our digital afterlife, May 6. https://www.heavenote.com/ blog/why-we-all-need-a-plan-for-our-digital-afterlife/. Accessed 1 August 2016. 
Horton, D., \& Wohl, R. R. (2006). Mass communication and parasocial interaction: Observations on intimacy at a distance. Psychiatry [Online], 19. http://www.participations.org/volume\%203/issue\% 201/301hortonwohl.htm.

International Council of Museums (ICOM). (1986). Code of professional ethics. http://archives.icom. museum/1986code_eng.pdf. Accessed 1 August 2016.

Karppi, T. (2013). Death proof: On the biopolitics and noopolitics of memorializing dead Facebook profiles. Culture Machine, 14. Retrieved from: www.culturemachine.net/index.php/cm/article/ download/.../528.

Kern, R., Abbe, E. F., \& Gil-Egui, G. (2013). 'R.I.P.: Remain in perpetuity. Facebook memorial pages.' Telematics and Informatics, 30, 2-10. http://www.sciencedirect.com/science/article/pii/S07365 85312000263. Accessed 29 October 2012.

Laouris, Y. (2015). The Onlife Manifesto. In L. Floridi (Ed.), The Onlife Manifesto: Being human in a hyperconnected era. Cham: Springer International Publishing. doi:10.1007/978-3-319-04093-6.

Lingel, J. (2013). The digital remains: Social media and practices of online grief. The Information Society, 29(3), 190-195. doi:10.1080/01972243.2013.777311.

Marwick, A. (2013). Status update: Celebrity, publicity and branding in the social media age. Yale University Press. Retrieved from: http://www.jstor.org/stable/j.ctt5vkzxr.

Marx, K. (1999). A contribution to the critique of political economy. Retrieved from: https://www. marxists.org/archive/marx/works/download/Marx_Contribution_to_the_Critique_of_Political_Economy. pdf. Originally published 1859.

Marx, K. (2000). Economic and philosophic manuscripts of 1844. Retrieved from: https://www.marxists. org/archive/marx/works/download/pdf/Economic-Philosophic-Manuscripts-1844.pdf. Originally published 1932.

Marx, K. (2015). Capital a critique of political economy volume I book one: The process of production of capital. Retrieved from: https:/www.marxists.org/archive/marx/works/download/pdf/CapitalVolume-I.pdf. Originally published 1876.

Mayer-Schönberger, V. (2009). Delete: The virtue of forgetting in the digital age. Princeton, NJ: Princeton University Press.

McCallig, D. (2013). Facebook after death: An evolving policy in a social network. International Journal of Law and Information Technology, 22(2), 107-140. doi:10.1093/ijlit/eat012.

Meese, J., Nansen, B., Kohn, T., Arnold, M., \& Gibbs, M. (2015). Posthumous personhood and the affordances of digital media. Mortality, 20(4), 408-420. doi:10.1080/13576275.2015.1083724.

Miller, R. (2016). Gmail has now 1 billion monthly active users. The Verge, February 1. http://www. theverge.com/2016/2/1/10889492/gmail-1-billion-google-alphabet. Accessed 1 August 2016.

Mitchell, L. M., Stephenson, P. H., Cadell, S., \& Macdonald, M. E. (2012). Death and grief on-line: Virtual memorialization and changing concepts of childhood death and parental bereavement on the Internet. Health Sociology Review, 21(4), 413-431. doi:10.5172/hesr.2012.21.4.413.

Montoya, A. (2012). From "the people" to "the human": HIV/AIDS, neoliberalism, and the economy of virtue in contemporary Vietnam. Positions: East Asia Cultures Critique, 20(2), 561-591.

Neate, R. (2014). How celebrities can make millions after death: Meet the man with the formula. The Guardian, November 22. https:/www.theguardian.com/music/2014/nov/22/celebrities-millionsafter-death-bob-marley-michael-jackson. Accessed 1 August 2016.

O'brien, M. (2015, August 28). Who owns your digital afterlife? Mercurynews.com. Retrieved from: http://www.mercurynews.com/business/ci_28721510/who-owns-your-digital-afterlife.

Pearson, M. P. (1999). The archaeology of death and burial. Texas A and M University Anthropology Series, (no 3), 250 pp. doi:10.1086/342438.

Roberts, J. (2016). Is this the most outrageous use of Snap Chat ever? Unilad.com. July 2. http://www. unilad.co.uk/viral/is-this-the-most-outrageous-use-of-snapchat-ever/. Accessed 1 August 2016.

Sherlock, A. (2013). Larger than life: Digital resurrection and the re-enchantment of society. The Information Society, 29(3), 164-176. doi:10.1080/01972243.2013.77730.

Smith, J. (2011). McAfee reveals average Internet user has more than $\$ 37,000$ in underprotected digital assets, September 27. http://www.mcafee.com/us/about/news/2011/q3/20110927-01.aspx. Accessed 1 August 2016.

Steinhart, E. (2007). Survival as a digital ghost. Minds and Machines, 17(3), 261-271. doi:10.1007/ s11023-007-9068-0.

Stokes, P. (2012). Ghosts in the machine: DO the dead live on in facebook? Philosophy and Technology, 25(3), 363-379. doi:10.1007/s13347-011-0050-7. 
Stokes, P. (2015). Deletion as second death: The moral status of digital remains. Ethics and Information Technology, 17(4), 1-12. doi:10.1007/s10676-015-9379-4.

Swan, L. S., \& Howard, J. (2012). Digital immortality: Self or 0010110? International Journal of Machine Consciousness, 4(1), 245-256. doi:10.1142/S1793843012400148.

Walter, T. (2015). Communication media and the dead: From the stone age to Facebook. Mortality: Promoting the Interdisciplinary Study of Death and Dying, 6275, 1-33. doi:10.1080/13576275. 2014.993598.

Wright, N. (2014). Death and the Internet: The implications of the digital afterlife. First Monday. doi:10. 5210/fm.v19i6.499. 